appeared only five years after the first edition is sufficient proof of its popularity. No radical changes have been made but the author has added some new illustrations and made a number of detailed changes in the process of revision. The readers who are already familiar with this book will be well aware of its clarity and conciseness.

The account of examination of joints, sadly lacking in many textbooks, here receives its due prominence. The diagrams are bold and clear, and the reproduction of radiographs is of a high standard. The book as a whole is of necessity somewhat dogmatic and there is only a scant account of the indications for operation and of operative technique. These comments, however, are in no sense a criticism, for the book is not intended to be used by the postgraduate student. As a textbook for undergraduates it is wholly admirable and thoroughly recommended.

\section{Local Analgesia Abdominal Surgery}

R. Macintosh and R. Burke Smith. Pp. viii +82 , illustrated. Second edition. Edinburgh and London: E. \& S. Livingstone. 1962. $25^{s}$.

It is a pleasure to find that yet another of the 'Oxford' books on local analgesia has run to a second edition.

Several of the diagrams have been redrawn and new techniques are described for prostatectomy in the poor risk patient and pylormyotomy in infants. As in the previous edition the excellence of the illustrations and clarity of the text are beyond criticism.

Shorter by 12 pages and increased in price by only 2s. $6 \mathrm{~d}$. this book is a 'must' for anyone contemplating the use of local analgesia for abdominal surgery.

\section{Injuries of the Knee Joint}

I. S. SMILliE O.B.E., Ch.M., F.R.C.S.(Ed.) F.R.F.P.S. Third edition. Pp. $x+536$, illustrated. Edinburgh and London. E. \& S. Livingstone. I962. £5 5 s.

It is eleven years since the second edition of Professor Smillie's well-known monograph on injuries of the knee joint was published. Those familiar with the previous editions will be well aware of the author's profound knowledge and abiding interest in the subject. No aspect of knee injuries is too small to be described, no condition too rare to be illustrated.

The new edition is a formidable work of 528 pages but there has been a thorough revision of the text and some sections from the previous edition have been replaced by new ones. The author draws on his extensive personal records, which include those of 5,000 meniscectomies, and on his own monograph on osteochondritis dissecans published in 1960. The entire production is a most handsome one and the illustrations lavish and clear; the reproduction of the colour photographs is extremely good.

The style of the book is unchanged. The author obviously has such a vast knowledge of his subject and has included so much detail in the text that the busy reader is apt to lose his way. This tendency is accentuated by the occasional over-long sentence and a slight obscurity of style. These, however, are minor criticisms of a book which is an erudite, thorough and masterly survey of the subject.

\section{Modern Trends in Orthopædics-Fracture Treat- ment}

Edited: J. M. P. Clark. Pp. viii + 259, illustrated. London. Butterworth. 1962. 60s.

What an excellent little book this is-a joy to hold and a pleasure to read. The illustrations are well pro- duced on good quality paper, and the size and shape of the book are exactly right. The editor has succeeded in marshalling a first-class team, each of whom has taken great trouble to produce an informative and wellwritten chapter. Throughout there is a hint of provocativeness which is most stimulating.

Among so many good contributions it is invidious, if not impossible, to express individual preferences, but your reviewer cannot resist mentioning the invaluable instructive and delightful chapters by $\mathrm{E}$. A. Nicoll on spine injuries, and by Frank W. Holdsworth on forearm fractures; but this is not to denigrate other chapters, which are all extremely good. After the editor's introduction there follow, in addition to the two chapters already mentioned, others on fractures of the femoral neck by Roland Barnes, the knee by G. R. Fisk, the femur by Norman Roberts, the ankle by G. K. Rose, the leg by J. C. Scott, the elbow by Denys Wainwright and on multiple injuries by R. S. Garden.

This is not simply another textbook on fractures. It aims at the man who is beginning to take personal responsiblity for the treatment of injuries, and for anyone in such a position it is indispensable. The young man sitting Fellowship or Mastership is not specifically catered for; nevertheless he should, indeed must, read this book-he will enjoy it and profit hugely from it.

\section{Vascular Surgery}

J. B. Kinmonth, C. G. Rob, F. A. Simeone. Pp. vii $+50 \mathrm{I}$, illustrated. London: Edward Arnold. 1962. $€ 5$

This is an excellent account of the theoretical background and practice of vascular surgery. The two British and one American author are separately responsible for different chapters, but all three authors have agreed on the content of each section. Thus an effort has been made to obtain a continuity of style and presentation. This is for the most part successful, but in view of the differing emphasis on various aspects of vascular surgery on the two sides of the Atlantic, it is not surprising that there is occasionally a compromise which leaves the reader rather confused.

The book deals with surgery of the whole circulation excluding the heart. It would be of great value to postgraduate surgery students and practising surgeons, although for the latter more space could have been given to technical problems encounted in the common vascular surgical operations.

There is one rather misleading statement on page 136 where it is stated that 'the principal arterial supply to the kidney may be occluded for as long as I hour and possible $1 \frac{1}{2}$ hours without permanent damage. Longer periods of ischaemia with survival may be possible in situations where a large collateral circulation exists'. This would seem to suggest that the kidney has a collateral circulation, but as has been known since the time of John Hunter, with the exception of minor capsular and extra capsular anastomoses, all the renal arteries are end-arteries.

The volume is clearly printed with good illustrations. There are surprisingly few typographical errors for a first edition. The whole field of arterial, venous and portal surgery is covered in a thoughtful and fairly comprehensive manner. The book can be thoroughly recommended, and is likely to run to many further editions. 